\title{
PROGRAMA DE ACOMPANHAMENTO DE EGRESSOS DA RFEPCT: UMA PROPOSTA INICIAL
}

\section{Program for Monitoring Graduates for FNVSTE: an Initial Protocol}

\author{
Katia Alves Campos ${ }^{1}$
}

\begin{abstract}
Resumo: O acompanhamento de egressos constitui uma exigência para os cursos superiores. Configura-se como necessidade de todas as instituições de ensino, embora ainda não exista no Brasil uma política fundamentada nessa linha. Há significativa diversidade dos níveis e das modalidades de ensino da Rede Federal de Educação Profissional, Científica e Tecnológica (RFEPCT). Por isso, é necessário propor logísticas que facilitem o levantamento de dados e possibilitem a aplicação de técnicas estatísticas para garantir consistência e convergência das decisões, além de permitir comparações longitudinais. Este projeto foi proposto com o objetivo de disponibilizar um protocolo inicial ao Programa de Acompanhamento de Egressos para a RFEPCT. Estruturaram-se e testaram-se questionários, para egressos e empregadores, que podem ser reorganizados para atender a demandas específicas de níveis, modalidades e cursos. Foram propostas técnicas estatísticas de simples aplicação e descritos resultados específicos dos egressos dos primeiros dez anos de três instituições da RFEPCT Mineira e dos possíveis empregadores do Instituto Federal do Sul de Minas (IFSULDEMINAS).
\end{abstract}

Palavras-chave: Perfil. Avaliação institucional. Avaliação de curso. Mundo do trabalho.

\begin{abstract}
The monitoring of graduates is a requirement for higher education courses and it is a necessity for all educational institutions, but there is not a policy based on this line in Brazil yet. Due to the diversity of teaching levels and modalities of the Federal Network of Vocational, Scientific and Technological Education (FNVSTE), logistic proposals are necessary to facilitate the data collection and allow the application of statistical techniques that guarantee consistency and convergence of decisions, besides longitudinal comparisons. This project was proposed in order to make an initial protocol available to the Program for Monitoring Graduates for FNVSTE, Questionnaires for graduates and employers were structured and tested, which can be reorganized to meet the specific demands of levels, modalities and courses. Statistical techniques of simple application were proposed and specific results of the graduates of the first ten years of the three institutions of FNVSTE of Minas Gerais as well as the results of the possible IFSULDEMINAS employers were described.
\end{abstract}

Keywords: Profile. Institutional evaluation. Course evaluation. Job Market.

\footnotetext{
${ }^{1}$ Doutora em Estatística e Experimentação Agropecuária pela Universidade Federal de Lavras - UFLA. Professora de Ensino Básico, Técnico e Tecnológico - EBTT do Instituto Federal do Sul de Minas Gerais - IFSULDEMINAS. http://orcid.org/0000-0002-0502-1842.E-mail: katia.campos@ifsuldeminas.edu.br
} 


\section{Introdução}

O acompanhamento de egressos constitui uma linha de pesquisa recorrente em todos os países, embora seja relativamente nova no Brasil, sendo a maioria das publicações representada por pesquisas independentes. A partir de 2004, houve um impulso nessa área, com a normatização do Sistema Nacional de Avaliação da Educação Superior (SINAES), quando se estabeleceram dez dimensões da avaliação das instituições de ensino superior (IES), dentre estas a Política de Atendimento a Estudantes e Egressos.

A Rede Federal de Educação Profissional, Científica e Tecnológica (RFEPCT), como as demais IES, oferece iniciativas de instituir um Programa de Acompanhamento dos Egressos. Contudo, enfrenta dificuldades, pois o universo dos profissionais formados na Rede é complexo, visto que, além dos cursos de graduação, oferta outros níveis de ensino que vão desde os cursos técnicos a pós-graduações stricto sensu.

Importante realçar que conhecer o ex-aluno como profissional não pode restringir-se ao cumprimento de exigências legais, pois, ao se conhecer o desempenho do egresso no mundo do trabalho, depara-se com muito mais. Pode-se verificar $e$.g. se há coerência entre os conteúdos curriculares e outras atividades formativas para o desempenho das atividades profissionais.

O acompanhamento de egressos estrutura-se como um instrumento de avaliação da qualidade dos cursos. Permite reavaliar os conteúdos curriculares e outras atividades formativas, pois conhecer o perfil do egresso, sua inserção ou não no trabalho, ou a continuidade nos sistemas de educação, resulta em obter informações que podem auxiliar na avaliação das Políticas Públicas e dos Programas de Educação Profissional. Essas informações podem, ainda, nortear os responsáveis pelas instituições de ensino a flexibilizar e a atualizar os currículos, para atenderem às demandas locais e regionais.

Validar pesquisas sobre egressos requer comparações longitudinais, obter representatividade e ser periodicamente aplicadas. Assim, para disponibilizar diretrizes para um Programa de Acompanhamento de Egressos, capaz de atender à diversidade da RFEPCT, foram estruturados modelos de questionários e trabalhou-se com duas populações: egressos formados nos primeiros dez anos de criação da RFEPCT de três instituições mineiras; e os responsáveis pelas empresas que ofertaram estágios em 2018 para o Instituto Federal do Sul de Minas Gerais (IFSULDEMINAS).

A análise dos resultados específicos possibilitou testar a proposta desse protocolo, que poderá iniciar um Programa de Acompanhamento de Egressos da RFEPCT. O Programa permitirá mostrar à sociedade a excelência educacional da Rede e disponibilizar informações capazes de nortear a adaptação dos currículos para atender a arranjos locais.

\section{A Rede Federal de Educação Profissional, Científica e Tecnológica}

O marco inicial das escolas técnicas no Brasil foi o Decreto 7.566, de 23 de setembro de 1909, do presidente Nilo Peçanha, criando dezenove Escolas de Aprendizes Artífices, nas capitais, com a missão de oferecer mão de obra especializada. Desde então, aconteceram várias mudanças tanto na legislação, quanto nas organizações curriculares (LEITE, 2015).

Sobre as organizações curriculares, espera-se que as mudanças continuem ocorrendo, pois as adequações dos currículos, segundo Moraes Filho, Carvalho Filha e Almeida (2017, p. 1), visam, no ensino superior, a preparar o egresso para o dinamismo social atual, em que só a 
"criação de um currículo amplo holístico", que integre teoria e prática, possa transformar "o ingressante em um profissional com capacidade crítica e reflexiva em sua prática profissional".

As mudanças na legislação culminaram na atual estrutura que deu origem à RFEPCT, em 29 de dezembro de 2008, com a Lei 11.892 (BRASIL, 2008), extinguindo 31 Centros Federais de Educação Tecnológica (CEFET), 75 unidades descentralizadas de ensino (UNEDS), 39 escolas agrotécnicas, sete escolas técnicas federais e oito escolas vinculadas às universidades, para formar os Institutos Federais de Educação, Ciência e Tecnologia (IF). Atualmente, a RFEPCT conta com "661 unidades, vinculadas a 38 Institutos Federais, dois Centros Federais de Educação Tecnológica (CEFET), a Universidade Tecnológica Federal do Paraná (UTFPR), 22 escolas técnicas vinculadas às Universidades Federais e o Colégio Pedro II" (BRASIL, 2020).

Configurou-se, então, uma rede formada pela junção de diversas instituições, algumas centenárias. Para atender aos arranjos locais, essas instituições são complexas, pois ofertam diversos níveis e modalidades de ensino e são, também, responsáveis por incrementar o número de vagas na educação gratuita e buscar a excelência na prestação de serviço.

Costa e Marinho (2018) apresentaram os trâmites que se seguiram desde a proposição do Projeto de Lei 3.775/2008 até a sanção presidencial. Argumentaram que a criação da Rede Federal atendeu os anseios, tanto das antigas escolas agrotécnicas, quanto dos CEFETs, e essas conquistas diminuíram "qualquer ímpeto para construção politicamente mais profunda". Concluíram que "O desleixo e a pouca profundidade na construção da normativa que originou os IFs não são condizentes com o tamanho e a importância dessas instituições” (p. 79).

Essa normativa ainda está sendo elaborada e, embora a RFEPCT tenha especificidades diferentes das universidades, as definições descritas por Chauí (1999) podem ser, sem muitas adaptações, estendidas à Rede. Segundo a autora, são possíveis três tipos de universidades: a clássica, quando a instituição está norteada para a construção de conhecimento; a funcional, voltada para a formação e capacitação para o mundo do trabalho e a operacional, com fim em si mesma, como uma organização. Percebe-se que a sociedade compreende a RFEPCT como uma miscelânea dessas definições, esperando, por se tratar de uma instituição de ensino, que haja a construção de conhecimentos aplicados, paralela à formação para o trabalho e, ainda, a busca - pela gestão - por financiamento junto à sociedade privada.

Como instituição relativamente nova, é inegável o impacto da RFEPCT na educação profissional brasileira, principalmente, porque é responsável por disponibilizar diversos níveis de ensino, na modalidade presencial ou no ensino a distância (EAD). Oferta cursos de formação continuada; ensino técnico e atende a diversos públicos: educação de jovens e adultos (EJA), ensino médio integrado à educação profissional e subsequente; ensino superior, com ênfase à licenciatura; e pós-graduação lato e stricto sensu. Atende, também, a arranjos produtivos, sociais e culturais locais que possibilitam o desenvolvimento científico, tecnológico e cultural da região onde os campi estão inseridos.

Frigotto (2018) afirma que, embora os IFs sejam relativamente novos, no contexto de educação brasileira, foram e continuam sendo responsáveis por grande incremento na oferta de vagas na educação gratuita, principalmente na modalidade de educação profissional e tecnológica, que visa qualificar cidadãos para atuação profissional, e acrescenta a interiorização do ensino profissional como novidade possibilitada pela criação dos IFs.

Embora seja expressivo o número de profissionais anualmente capacitados pela RFEPCT para o trabalho, existe diferença entre a oferta de vagas e o número de egressos. Nesse 
sentido, verificou-se que o índice de conclusão está numa tendência crescente, já que as taxas passaram de 43,47\%, em 2017, para 45,58\%, em 2018, embora ainda não tenha atingido 50\% das matrículas (BRASIL, 2019).

Há necessidade, portanto, de aumentar esses índices e buscar mecanismos para ampliar a permanência e o êxito dos discentes, de forma a minimizar a evasão, não só porque é a primeira prestação de contas à sociedade, mas como forma de assegurar a todos o direito à educação de qualidade a que a RFEPCT se propõe. Chauí (1999, p. 6) questionava o critério de avaliação a que as instituições de ensino estavam submetidas. Segundo a autora, já existia "uma inversão tipicamente ideológica da qualidade em quantidade". Entretanto, o impacto da Rede na sociedade está muito além do número de profissionais capacitados.

Uma possibilidade de mostrar à sociedade a efetividade das instituições de ensino está no estudo de seus egressos. Segundo Deluiz (2003), as Políticas Públicas e os Programas de Educação Profissional podem ser avaliados a partir do acompanhamento dos egressos. Paul $(2015$, p. 321) afirma que o resultado desse tipo de estudo pode ser capaz de "melhorar o ensino superior e proporcionar importantes informações aos estudantes e suas famílias".

Portanto, por meio do acompanhamento dos ex-alunos no mundo do de trabalho, podem-se obter informações que mostrem, além da quantidade de egressos, a diferença que a Rede fez na vida dos formandos.

\section{O Acompanhamento de Egressos}

A pesquisa de acompanhamento de egressos é recorrente. Segundo Paul (2015), há pesquisas datadas desde a década de 30, nos Estados Unidos, mas se estabeleceram após os anos 60 na Europa, após o aumento do número de vagas para graduação. No Brasil, a partir dos anos 70, surgiram os primeiros desses estudos.

O acompanhamento é descrito como "ferramenta estratégica", capaz de criar "condições para avaliar o processo de inserção no mundo do trabalho, o seu perfil e a percepção dos egressos em relação à formação recebida na sua trajetória" (BRASIL, 2007, p. 10).

No país, as publicações são representadas principalmente por iniciativas independentes, e essa área ganhou maior impulso após 2004, dadas as exigências do SINAES, pois, conforme Brasil (2015, p. 44), "especificamente no instrumento de avaliação institucional externa está previsto o acompanhamento de egressos”. Em Brasil (2004, p. 7), consta sobre o SINAES:

Instituído pela Lei n ${ }^{\circ} 10.861$, de 14 de abril de 2004, o Sistema Nacional de Avaliação da Educação Superior (SINAES) fundamenta-se na necessidade de promover a melhoria da qualidade da educação superior, a orientação da expansão da sua oferta, o aumento permanente da sua eficácia institucional, da sua efetividade acadêmica e social e, especialmente, do aprofundamento dos seus compromissos e responsabilidades sociais.

Assim, com o objetivo de avaliar as IES, para promover melhoria na oferta dos cursos e novos credenciamentos, foi instituído o SINAES que, desde então, integra três modalidades de avaliação das IES, dos cursos de graduação e de desempenho dos estudantes.

A primeira modalidade, avaliação institucional, subdivide-se em avaliação externa e autoavaliação, que fica a cargo das Comissões Próprias de Avaliação (CPA), responsáveis por divulgar, anualmente, um relatório redigido conforme o Roteiro de Autoavaliação. No quarto 
capítulo do Relatório, definem-se dez dimensões, sendo o estudo dos egressos "Núcleo de temas optativos" em duas delas, e objetivo principal da nona dimensão (BRASIL, 2004).

Mesmo sendo descritos como optativos na primeira dimensão - “A missão e o Plano de Desenvolvimento Institucional" - pergunta-se "qual é o perfil esperado dos egressos da instituição?”; e na segunda dimensão, em que se aborda: "A política para o ensino, a pesquisa, a pós-graduação, a extensão e as respectivas normas de operacionalização, incluídos os procedimentos para estímulo à produção acadêmica, as bolsas de pesquisa, de monitoria e demais modalidades", busca-se trazer no relatório a resposta à pergunta: "os currículos e programas de estudos de cada curso respondem ao perfil do egresso?". São solicitados no item "Documentação, dados e indicadores dessa dimensão", respectivamente, "descrição do perfil de egressos (conhecimentos e competências que devem adquirir durante a sua permanência na IES)" e "indicadores de atuação profissional dos egressos" (BRASIL, 2004, p.18-21).

Mais adiante, Brasil (2004, p. 29), é descrita a nona dimensão "Políticas de atendimento a estudantes e egressos", em que uma das abordagens deve ser o "acompanhamento de egressos e de criação de oportunidades de formação continuada". A descrição do núcleo básico e comum sonda a "inserção profissional dos egressos; participação dos egressos na vida da IES." E o núcleo de temas optativos investiga o seguinte:

\footnotetext{
- Existem mecanismos para conhecer a opinião dos egressos sobre a formação recebida, tanto curricular quanto ética? Quais são?

- qual a situação dos egressos? Qual o índice de ocupação entre eles? Há relação entre a ocupação e a formação profissional recebida?

- existem mecanismos para conhecer a opinião dos empregadores sobre os egressos da instituição? Quais?

- é utilizada a opinião dos empregadores dos egressos para revisar o plano e os programas? Como é feita?

- existem atividades de atualização e formação continuada para os egressos? Quais? há participação dos egressos na vida da instituição? Como?

- que tipos de atividades desenvolvem os egressos? Que contribuições sociais têm trazido? (BRASIL, 2004, p. 30).
}

Essas perguntas, são basicamente as mesmas questões levantadas em qualquer pesquisa de acompanhamento de egressos. A descrição da "Documentação, dados e indicadores desta dimensão" aborda dados anteriores à entrada do discente na IES: " $\mathrm{n}^{\circ}$ de candidatos, $\mathrm{n}^{\mathrm{o}}$ de ingressantes"; dados da vida acadêmica " $n^{\circ}$ de estudantes matriculados por curso, $n^{\circ}$ médio de estudantes por turma, $n^{\circ}$ de eventos realizados, $n^{\circ}$ de participações em eventos, $n^{\circ}$ de trabalhos de estudantes publicados"; dados de incentivo à iniciação científica " $\mathrm{n}$ " de estudantes com bolsas, $\mathrm{n}^{\mathrm{o}}$ de bolsas e estímulos concedidos, $\mathrm{n}^{\mathrm{o}}$ de intercâmbios realizados"; índices como "taxa de sucesso na graduação, grau de participação estudantil, tempo médio de conclusão do curso, aluno tempo integral/professor, aluno tempo integral/funcionário técnico-administrativo" e nominalmente descrevem as "pesquisas ou estudos sobre os egressos e/ou empregadores dos mesmos, dados sobre a ocupação dos egressos, evidências de atividades de formação continuada para os egressos" (BRASIL, 2004, p. 30). Portanto, até no acompanhamento de egresso que foi normatizado para o ensino superior, pelo SINAES, deve conter outras informações, não apenas índices, pois, segundo Brasil (2004), devem-se levantar informações capazes de aumentar a eficácia das instituições tanto acadêmica quanto socialmente.

E, no universo da RFEPCT? Como agir? Deve-se fazer esse acompanhamento apenas para os cursos de graduação, satisfazer a legislação vigente e deixar de lado a diversidade existente? O que se busca na rede é desenvolver acompanhamentos que sejam eficazes, não só 
para responder à legislação do ensino superior, mas também para dar informações capazes de contribuir para a excelência de oferta de capacitação profissional em todos os níveis ofertados. O entendimento de Paul (2005) confirma que a pesquisa de ex-alunos não deve ser apenas um dispositivo para "satisfazer as autoridades responsáveis", mas deve proporcionar informações capazes de ajudar aos gestores nas tomadas de decisões.

Antes da instituição da RFEPCT, em 2007, foi divulgada a Pesquisa Nacional de Egressos dos Cursos Técnicos de Nível Médio das antigas instituições que formaram a rede. Para realizar esse relatório, foram contatadas as 153 instituições federais que ofertaram esse nível de ensino, entre 2003 e 2007, e obtiveram-se os contatos telefônicos de 72.654 ex-alunos, que resultaram no retorno de $85 \%$ das instituições. Desses, foram sorteados 2.649 contatos, para responderem, por telefone, questões sobre empregabilidade dos egressos; continuidade de estudos e adequação da formação profissional recebida. A amostra foi estratificada por região e por área, agrícola ou industrial (BRASIL, 2007). Embora contassem com uma equipe multidisciplinar e tivessem citado a utilização de um software estatístico pago, apresentaram apenas porcentagens e as comparações por sexo e por região.

Diante das diversas possibilidades do estudo, e. g., apontaram que uma das maiores diferenças estava na empregabilidade das mulheres e, por isso, uma das sugestões foi o desenvolvimento de políticas públicas para elas. Embora tenha sido realizado no período préformação da RFEPCT, já se afirmava que o acompanhamento dos egressos possibilitou perceber o desenvolvimento local e regional, que constitui um aspecto que atualmente é parte da missão de quase todos os Institutos Federais (BRASIL, 2007, p. 34):

[...] aspecto importante no resultado da pesquisa, que a localização do trabalho do egresso estabelece-se na região onde o mesmo realizou o curso técnico, o que vem reafirmar o papel que a Rede Federal de EPT assume como agente articulador e promotor do desenvolvimento local e regional.

Outros trabalhos mais atuais avaliaram os egressos de cursos técnicos após a RFEPCT. Sampaio (2013) utilizou como população de estudo os egressos do Instituto Federal do Rio Grande no Norte. Pôde concluir que a interiorização dos institutos e a expansão da educação profissional conseguiram descentralizar as oportunidades de trabalho e foram importantes para a maioria dos egressos. Entretanto, na regionalidade de seu estudo, sua absorção pelo mercado de trabalho ainda não é suficiente para a demanda. Essa informação poderia ter sido utilizada para adequações na oferta dos cursos que a região pudesse demandar.

Andrade e Barbosa (2017) estudaram os egressos dos cursos técnicos de Morrinhos, no período de 2010 a 2014 , e obtiveram como resultado que $86 \%$ destes continuaram a estudar em áreas correlatas ao curso técnico e $30 \%$ trabalhavam na área de formação técnica. Ao entrevistarem os empregadores, receberam, por unanimidade, a informação de que a formação técnica é decisiva na seleção do empregado. Ainda afirmaram que há "vinculação entre a Educação Profissional e Tecnológica e o mercado de trabalho", pois "os indivíduos que buscam esse tipo de formação pretendem ingressar ou se reinserir no mercado de trabalho". Assim, as afirmações levantadas no acompanhamento podem respaldar ações específicas da gestão.

Dentro de uma mesma instituição e de um mesmo nível, apenas mudando os cursos, percebem-se tendências diferentes. Os egressos dos cursos técnicos do IFSULDEMINAS, Campus Machado, do período de 2009 a 2016, foram analisados por meio de informações públicas em redes sociais. Obteve-se que, para os formandos em Agropecuária encontrados, $52,7 \%$ estavam no mercado de trabalho; destes, $57 \%$ atuam em áreas correlatas ao curso (NERY 
et al., 2019). Dos formandos que continuam estudando, a maioria $(77,4 \%)$ continuou na área (ROCHA et al., 2019). Já, para os cursos de Alimentos e de Informática, dos ex-alunos encontrados em perfis públicos, existe maior número ainda fora do mercado de trabalho, respectivamente, 69 e 71\% - na área de alimentos, constatados por Caproni et al. (2019) e, na área de informática, por Bastos et al. (2019), estando estes, na maioria, fora da área do curso concluído. Esses resultados corroboram aqueles dos estudos de Manzke, Gonzales Saller e Gil (2013) que afirmaram haver uma dicotomia, do ponto de vista dos estudantes, sobre a função do ensino técnico integrado. Entretanto, vale ressaltar que, para esse nível, o foco deve ser o preparo para o mercado sem, contudo, impossibilitar a continuidade no sistema educacional. Pelos dados, obtidos, a instituição tem possibilitado a escolha.

No geral, encontram-se muitos trabalhos publicados sobre egressos, que, na maioria das vezes, possuem motivações independentes A pesquisa dos termos "Acompanhamento de Egressos", no período de 2015 a 2019, após a exclusão dos textos de áreas não educacionais; retornou em 190 artigos. Destes, 2,0\% referem-se a estudos de cursos técnicos; a maioria $(82,4 \%)$ aos estudos para cursos superiores; seguidos pelos cursos de pós-graduação $(15,6 \%)$.

Almejou-se estabelecer uma comparação entre esses estudos. Entretanto, não foi possível, dadas as diferenças na amostragem, probabilística ou não; no número de envios, mínimo de 10 e máximo de mais de $100 \mathrm{mil}$; no percentual de retorno, de um a 100\%; na forma de aplicação, questionamento em eventos, que têm maior adesão; envio de e-mails, cujo retorno é baixo; entrevistas, por telefone, com a maior taxa de participação; buscas em redes sociais; na metodologia utilizada para a análise das respostas; e principalmente nos objetivos.

Institucionalmente, a criação de um Programa de Acompanhamento de Egressos (PAE) reforça a finalidade de verificar se a política de inserção profissional da instituição está sendo eficaz. Por exemplo, no IFSULDEMINAS, o Acompanhamento dos Egressos é uma das metas estabelecidas no Plano de Desenvolvimento Institucional, que criou o PAE, para ser "sistemático e contínuo, visando, principalmente, ao aproveitamento dos resultados obtidos na elaboração ou na reestruturação de currículos” (IFSULDEMINAS, 2014).

Essas metas são, geralmente, buscadas por toda a RFEPCT e reproduzem o entendimento de Machado (2002) que, há cerca de duas décadas, propunha constante pesquisa dos concluintes da educação profissional, para atender às demandas da sociedade em geral.

Outro ponto de vista que deve ser levado em consideração, no acompanhamento dos egressos, é o dos empregadores. Até do SINAES, há a menção de procura por mecanismos que evidenciem as opiniões sobre a formação dos profissionais e como essas opiniões são utilizadas para adequar os planos e programas dos cursos (BRASIL, 2004).

Paul (2015) conseguiu fazer um apanhado das pesquisas de acompanhamento de egressos de graduação, no mundo, com ênfase na França, Alemanha, Grã-Bretanha e Itália, cujas experiências retornaram elogios de muitos autores da área, pois se configura como exemplo de programa bem-sucedido, porque se caracteriza como uma "rede social" em que o discente é convidado a aderir, nos últimos meses do curso. A partir de então, são entrevistados, ao longo dos anos. Os apontamentos do autor são levados em consideração para a proposta desse protocolo, pois o autor afirma que as pesquisas não podem seguir modismos. Precisam, por certo, de apresentar a capacidade de comparação longitudinal, ser repetidas regularmente e possibilitar uma vasta amostragem.

Portanto, uma proposta para atender à diversidade da RFEPCT deve ser dinâmica e permitir mostrar comparações e divergências, tanto para satisfazer as exigências do SINAES, 
como para conhecer a realidade de seus ex-alunos. Isso porque o acompanhamento de egressos visa a servir de feedback aos gestores para tomadas de decisão, e.g., nas adequações dos currículos, de modo a atender demandas locais ou mesmo regionais e não apenas para quantificar os ex-alunos que estão no mercado de trabalho em áreas afins às cursadas nas instituições. Sendo assim, faz-se necessário estruturar um protocolo de fácil e rápida aplicação e análise, capaz de associar e correlacionar as respostas dos questionários, cujos resultados possam ser apresentados à sociedade.

\section{Metodologia}

De modo a sugerir um protocolo para iniciar um PAE destinado à RFEPCT, foram elaborados e testados dois questionários propícios a atender tanto à legislação quanto à diversidade da rede, em duas frentes: o ponto de vista dos egressos e dos empregadores.

Os resultados específicos não fazem parte do foco deste artigo. Eles foram encaminhados aos gestores e publicados em periódicos. O principal objetivo, aqui apresentado, foi testar o instrumento e a metodologia proposta, de modo que pudesse ser planejada uma logística de aplicação e de análise dos resultados, fechando a proposta para o protocolo inicial.

Para estruturar os questionários, que devem ser considerados mínimos, utilizaram-se os modelos disponíveis e encontrados com a pesquisa em referencial bibliográfico, realizada de maneira a conhecer o que já foi construído e ter "um primeiro contato, que recupere determinado trabalho, possibilitando a circulação e intercâmbio entre a produção construída e aquela a construir" (FERREIRA, 2002, p. 261). Consultaram-se os campi da RFEPCT Mineira, de forma a utilizar as ações que já são feitas e os questionários já aplicados.

Utilizou-se a ferramenta de criação de formulários Google Forms, disponível em Google (2020), por ser uma ferramenta gratuita, de fácil manuseio e que gera os gráficos de frequências simples e o banco de dados que pode ser exportado para planilhas eletrônicas em que todas as estatísticas propostas e representações gráficas de comparações bivariadas e avaliação da instituição e do curso podem ser calculadas.

Para conhecer os egressos, após a estruturação do primeiro questionário, de forma a validá-lo, foram realizadas duas aplicações por convite; a primeira em redes sociais e a segunda por envio de e-mails. O primeiro teste foi disponibilizado no portal do IFSULDEMINAS, com o convite para a população dos egressos, formados entre os anos de 2014 e 2018 . A população estimada totalizava 1.500 formandos. O critério de inclusão foi ter acesso às redes sociais da instituição. Após seis meses, os dados foram tratados, para se proceder à primeira validação (RIBEIRO; CAMPOS, 2019; FRANCISCO, PELÚCIO; CAMPOS, 2019) ${ }^{2}$.

A partir das análises, foram realizadas modificações nas questões, como a retirada de questões dúbias e automações, buscando-se agilizar o preenchimento; foi reestruturado o questionário ${ }^{3}$ e pôde-se realizar o segundo teste do instrumento para os egressos. Os critérios

\footnotetext{
${ }^{2}$ A validação do questionário foi realizada de forma separada para os ensinos técnico e superior, tendo em vista que são públicos distintos e necessitam de abordagens específicas.

${ }^{3}$ O questionário já disponibilizado às chamadas anteriores, adaptado para utilização na versão inicial e passível a novas adaptações, conforme nível e público investigado, encontra-se transcrito na seção de Apêndice do Capítulo 2: "Proposição de um protocolo para acompanhamento de egressos da Rede Federal de Educação Profissional", In: Observatório da Educação Profissional e Tecnológica: Diagnóstico da Rede Federal de Educação Profissional, Científica e Tecnológica de Minas Gerais (No Prelo).
} 
de inclusão na população dessa segunda rodada de aplicação do questionário foram: ter concluído um curso no período entre 2009 e 2018, e estar na relação dos mais de 46 mil endereços eletrônicos encaminhados pelos responsáveis do acompanhamento de egressos de uma das três instituições participantes: Centro Federal de Educação Tecnológica de Minas Gerais (CEFET-MG), Instituto Federal de Minas Gerais (IFMG) e IFSULDEMINAS.

Foi encaminhado, por esse endereço eletrônico, o link do convite para a participação na pesquisa, a cópia do Termo de Consentimento Livre e Esclarecido (TCLE), um breve resumo da pesquisa e o contato para tirar dúvidas. Para ter acesso às perguntas, foi necessário, primeiro, ler o resumo do $\mathrm{TCLE}^{4}$, depois clicar em "aceito". Caso não fosse dado esse aceite, o participante era encaminhado para a seção "Agradecemos sua participação".

Foram estudadas diversas técnicas estatísticas, sugeridas para o tratamento dos dados provenientes de questionários. A estruturação do instrumento com questões fechadas e o uso de itens tipo-Likert, decorreu da facilidade de entendimento, por serem questões intuitivas e de larga utilização; e por proporcionar análise dos dados de modo simples e também possibilitar a apresentação visual dos resultados.

Para a construção do perfil, optou-se por questões fechadas que pudessem ser apresentadas em forma percentual e que pudessem ser comparadas com a população original. Buscaram-se informações socioeconômicas, atividade atual e conhecer se essa atividade está em área correlata ao curso concluído. Para os egressos atualmente empregados na área do curso concluído, foi estimado o intervalo de confiança do tempo da formatura, até a sua efetivação como profissional, de modo a propor que no período após o desligamento da instituição deve ser feita a pesquisa com o egresso. Foram estimadas as estatísticas descritivas univariadas, que podem ser vistas em profundidade em diversos autores como Ferreira (2009). Visando abranger tanto os egressos já empregados quanto os egressos que continuam no sistema educacional, foram destinadas questões específicas a cada subgrupo, de acordo com a atividade atual.

As associações bivariadas entre o nível do curso concluído e a atividade atual; nível do curso e a atividade atual ser na área do curso concluído; atividade atual e esta ser na área do curso concluído foram testadas por meio do Coeficiente de Contingência de Pearson $\left(\mathrm{C}^{*}\right)$ descrito, entre outros autores, por Lira e Chaves Neto (2006). Pela construção desse estimador, apenas os valores nulos indicam não haver associação entre os níveis estudados.

Para a avaliação da interferência da instituição na vida do egresso; da própria instituição, nas áreas de ensino/pesquisa/extensão, do relacionamento da comunidade, da infraestrutura, do desenvolvimento de habilidades; do curso concluído e da contribuição do mesmo para a formação profissional, utilizaram-se questões tipo-Likert (BROW, 2011). As estruturas foram criadas, usando-se a escala hedônica, atribuindo-se notas de 1 a 5 , respectivamente, para muito insatisfeito até muito satisfeito. Nessas análises, utilizou-se a metodologia do ranking médio. Foram estimadas as notas médias atribuídas a cada item e, de acordo com o padrão, classificou-se a avaliação como "fragilidade" (notas médias menores e iguais a 3), "normal esperado" (médias acima de 3 e menores e iguais a 4,5) e "potencialidades" (notas superiores a 4,5), graficamente representadas pelas cores vermelha, amarela e verde.

\footnotetext{
${ }^{4}$ A primeira proposta de pesquisa: Atuação dos Egressos do IFSULDEMINAS, foi aprovada no parecer do Comitê de Ética em Pesquisas (CEP) sob o número 3530194, em agosto de 2019; entretanto, a Resolução 510/2016, Brasil (2016) normatiza em Ciências Sociais a liberação do registro e da avaliação pelo CEP pesquisas realizadas de forma censitária e sem identificação dos participantes.
} 
A consistência e confiabilidade das respostas foram testadas pelo alfa de Cronbach (CRONBACH, 1951), uma estatística que mede o padrão de resposta da população estudada. Segundo Brow (2011), o valor estimado deve ser superior a 0,80, para que as respostas dos participantes sejam consideradas consistentes e convergentes. O teste foi aplicado, para a totalidade; por nível de ensino (técnico, graduação e pós-graduação); por área da atividade atual (área do curso ou não); e por ocupação atual (no trabalho ou no sistema educacional).

O questionário conta também com perguntas que levam o egresso a atualizar seus dados e informar contatos da empresa em que trabalha, para que esta possa participar da pesquisa como empregador. Nenhuma questão apresentou obrigatoriedade de resposta.

A segunda etapa abordada foi a obtenção do ponto de vista dos empregadores, que pode ser utilizada para atestar a coerência dos conteúdos curriculares e outras atividades formativas para o desempenho das atividades profissionais.

Para iniciar um levantamento do ponto de vista do egresso empregado no exercício da sua profissão e levar em conta o feedback dos empregadores, seria necessário um banco de dados dessas empresas, que não é de fácil acesso como a relação dos formandos, optou-se por testar o questionário com oito perguntas fechadas e uma aberta, considerando-se como população as empresas que ofertaram estágios no ano de 2018 para os discentes do IFSULDEMINAS. Portanto, a população pode ser considerada como de "possíveis empregadores", capazes de mensurar a ação dos discentes enquanto estagiários e a probabilidade de contratá-los.

Desenvolveu-se e testou-se um questionário capaz de ajudar a entender o ponto de vista do possível empregador. As questões iniciais localizam a empresa espacialmente, quanto ao ramo de atuação e quanto ao porte. Essas questões foram expostas descritivamente e foram utilizadas para segmentar a opinião dos participantes sobre questões dos fatores que influenciaram a contratação e a existência de funcionários e de estagiários, caso houvesse um número suficiente de respondentes. Essas associações, bivariadas, foram testadas pelo $\mathrm{C}^{*}$, conforme critérios já descritos anteriormente.

Para a oitava questão, que conta com nove itens tipo-Likert, utilizaram-se os mesmos processos adotados para esse tipo de item do questionário dos egressos; desde a pontuação pelo participante com a escala hedônica de cinco pontos com uma opção extra: "não tenho opinião", visto que algumas ações desenvolvidas nas instituições podem não ser de conhecimento das empresas, como a oferta de atividades de extensão. Também, foram realizados o teste da consistência e confiabilidade das respostas pelo alfa de Cronbach e feita a análise pelo ranking médio e apresentação por cores.

Os resultados para cada uma das três pesquisas foram disponibilizados em relatórios específicos, posteriormente encaminhados aos gestores, de modo que, ao conhecer a realidade de seus egressos, sua absorção no mercado de trabalho, os pontos positivos e os negativos de suas formações, possam, se aplicados longitudinalmente, embasar ações e flexibilizar os currículos, a fim de minorar os pontos negativos e ressaltar os positivos. Foram, também, posteriormente, publicados em revistas da área.

Neste texto, a comparação dos bancos de dados foi utilizada para determinar a logística da periodicidade de aplicação para a qual foi utilizado o tempo para entrar no mercado de trabalho, suas medidas de tendência central e de dispersão; e o tempo de disponibilização foi calculado pela análise das frequências acumuladas. 


\section{Resultados e Discussão}

Como não poderia ser diferente, dada a complexidade da RFEPCT, o protocolo que será sugerido é apenas o ponto inicial e deve ser ainda discutido, para que seja transformado em um Programa de Acompanhamento do Egresso para a Rede.

A iniciativa aqui apresentada pode ser reestruturada para atender a demandas específicas, como abertura de novos níveis de um curso ou área, de cursos e níveis específicos. Também, atende a demandas do SINAES, para o ensino superior, de forma a auxiliar o trabalho das CPAs. A sugestão apresentada é otimizar e utilizar o processo já realizado pelas CPAs no ensino superior, para satisfazer o SINAES e expandi-lo para todos os níveis, com propostas de tratamento dos dados obtidos e estudos longitudinais.

Com a elaboração da revisão bibliográfica, pôde-se classificar a pesquisa de acompanhamento de egressos em três tipos, cada um deles determinado por um objetivo geral ${ }^{5}$ diferente, e pela forma de obtenção dos seguintes dados: a) divulgar o perfil do egresso, conhecimentos e competências adquiridas para a atuação profissional; b) saber como está o egresso após a formatura; c) conhecer o ponto de vista dos empregadores.

Em todos os casos, é necessário haver um banco de dados atualizados dos ex-alunos. Este e toda a comunidade acadêmica, devem ser motivados a participar de pesquisas.

Para alcançar esse primeiro objetivo, basta utilizar os dados internos das instituições e pode-se descrever o número de formados, por período, nível, curso, dados socioeconômicos que as instituições disponibilizam para a sociedade e utilizar as informações dos projetos pedagógicos para descrever conhecimentos e competências que devem ser adquiridas pelos discentes, ao concluir os estudos. Assim seria necessário: banco de dados institucional atualizado, padronizado e de fácil acesso, de preferência que seja feito em linha, iniciando, ainda, como candidato. Principalmente com a conscientização crescente de toda a comunidade acadêmica, com a criação de uma estrutura de cadastro dos alunos, para a qual pode ser utilizado o próprio SUAP, e com o acesso a novas tecnologias espera-se que cada vez mais os ex-alunos participem. Desse modo, poderiam ser obtidos todos os dados pessoais e os dados socioeconômicos na entrada na instituição, dados do discente: notas, reprovações, evasão, participação em projetos de ensino, pesquisa e extensão, etc. A disponibilização desses dados à população poderia fomentar diversas pesquisas em áreas como, por exemplo, permanência e êxito, evasão.

Os dois últimos tipos de objetivos, isto é, saber como está o egresso e como o empregador percebe o profissional formado pela rede, requerem a aplicação de um questionário e, ou realização de entrevistas aos egressos e aos empregadores. $\mathrm{O}$ formulário de ambos os questionários foi estruturado para permitir que os itens possam ser rearranjados e aplicados parcialmente. E que sejam acrescentadas questões para atender a objetivos específicos.

Uma dúvida que pode surgir sobre pesquisas com a utilização de questionário e, ou entrevista é a necessidade de submissão aos Comitês de Ética em Pesquisa (CEP). O modelo disponibilizado mantém a pergunta de aceite para participar da pesquisa como forma de, ao apresentar o resumo do TCLE, assegurar informações ao participante. Entretanto, o PAE de Acompanhamento de Egressos, não necessariamente, deve ser registrado e avaliado pelos CEP,

\footnotetext{
${ }^{5}$ Que ainda podem apresentar objetivos específicos definidos por segmentações diversas, como nível, área do curso, campi, instituição, região, sexo, faixa etária entre outros.
} 
pois, segundo o parágrafo único do primeiro artigo da Resolução 510/2016, "Não serão registradas nem avaliadas pelo sistema CEP/CONEP", em oito casos específicos descritos em seus incisos (BRASIL, 2016). E o acompanhamento de egressos se enquadra em pelo menos três dessas exceções, porque não serão identificados os participantes: "I - pesquisa de opinião pública com participantes não identificados"; porque na maioria das vezes não serão feitas amostragens e todos os formados de um período e/ou curso receberão o convite para participar: "IV - pesquisa censitária" e, principalmente, porque se configura como uma "VII - pesquisa que objetiva o aprofundamento teórico de situações que emergem espontânea e contingencialmente na prática profissional, desde que não revelem dados que possam identificar o sujeito" da resolução 510/2016 (BRASIL, 2016).

A forma de aplicação sugerida, considerando-se a facilidade e o menor custo é o envio dos questionários por endereço eletrônico. Entretanto, pode ser utilizada a aplicação em forma de entrevista, por exemplo, por contato telefônico. Ambas as formas apresentam desvantagens. $\mathrm{O}$ envio de questionários on-line apresenta baixo retorno, conforme Marconi e Lakatos (2005) que afirmam não ser superior a $25 \%$. E o contato por telefone aumenta a demanda de pessoal treinado para aplicação das entrevistas e que possam ficar muitos dias disponíveis para a ação.

Especificamente para o segundo tipo de pesquisa: saber como está o egresso após a formatura, é preciso entrar em contato com os ex-alunos, e pelo questionário pode-se levantar informações se o egresso está no mercado de trabalho; se continuou os estudos em outros níveis, ou mesmo em formação continuada; se se mantém na área do curso concluído na rede e, ainda, podem-se conseguir avaliações institucionais e referentes aos cursos concluídos. É necessário o mesmo banco de dados institucional, que foi tratado para o primeiro objetivo - traçar o perfil do aluno, e deve apresentar informações, como endereços eletrônicos e, ou telefônicos, para que possa ser utilizado para definir a população do estudo.

Toda pesquisa deve ser iniciada com a escolha da forma que será executada. Se será realizado um censo, isto é, o envio em massa do convite para participação na pesquisa, ou se será utilizada uma amostra, sorteada a partir do banco de dados, de modo que possa ser representativa. A descrição dessas técnicas não cabe no corpo deste trabalho, mas pode ser vista, entre outros autores, em Oliveira (2014).

Algumas sugestões de realização para se fazer o acompanhamento anual dos egressos, de modo a atender também às demandas do SINAES, para o ensino superior e estendê-las a todos níveis, incluem disparar e-mails para todos os formados, em forma censitária. Isto porque, como o número de formandos por turma, por ano, comumente não é muito superior a uma centena, a amostragem não é muito diferente da própria população.

Entretanto, se o objetivo é estudar uma área específica para a criação, por exemplo, de um curso de pós-graduação, ou mesmo para divulgar o mercado de trabalho para novos discentes, e já são ofertados os níveis técnico e graduação, sugere-se que o acompanhamento do egresso deva seguir a estrutura de amostragem probabilística, sendo, em cada caso, estruturada, no mínimo, como estratificada ou por conglomerados. Assim, depois de definido o objetivo, deve-se limitar um período de tempo e, no banco de dados da instituição, levantar os contatos e o número de egressos, para estimar o tamanho da amostra estratificada. Por exemplo, a estratificação pode ser realizada pelo nível de ensino, em que serão sorteados os egressos dos cursos técnicos e de graduação, para só então enviar os questionários para os endereços eletrônicos e, depois do tempo determinado, entrar em contato por meio telefônico com aqueles 
participantes sorteados que não responderam ao questionário. Se esses cursos forem ofertados em mais de um campus, poderia ser feita a amostragem por conglomerados.

Para exemplificar, em números, no segundo teste do questionário, cujo número de egressos foi superior a 46 mil, nas três instituições participantes, o tamanho da amostra, para um nível de confiança de 3\%, deveria ser de 1.086, número muito próximo do número de respondentes (1.087). Entretanto, nada pode ser afirmado sobre a confiança nesse teste, porque os respondentes deveriam ter sido sorteados, o que caracterizaria uma amostragem probabilística, e apenas estes receberiam o convite para participar da pesquisa. Ressalta-se que, ao estratificar por instituição, seriam necessários os sorteios respectivos de 1.053, 1.018 e 1.085, para o CEFET-MG, IFMG e IFSULDEMINAS. Assim, percebe-se que a estratificação sempre amplia o número de participantes.

Para estruturar o questionário, foi realizada a pesquisa documental; e utilizou-se principalmente os itens pedidos para a autoavaliação institucional em Brasil (2004) e o modelo aplicado em Brasil (2007). De modo a conhecer as ações que já estavam sendo aplicadas na RFEPCT Mineira, encaminhou-se uma explicação do projeto para os contatos das Pró-reitorias de Extensão dos cinco Institutos Federais e para o setor responsável do CEFET-MG. Junto à explicação, houve o pedido de informação sobre o que já estava sendo feito e, se possível, do questionário que já estivesse sendo aplicado.

Foram enviados 94 e-mails para os campi, a amostragem se restringiu para 78 contatos ou porque não foram encontrados ou porque ainda não faziam o acompanhamento de egressos, por ainda não terem turmas formadas. Destes, 5,2\% entraram em contato, apenas querendo conhecer mais o projeto. Efetivamente só $7,7 \%$ responderam ao questionamento e encaminharam os formulários utilizados. Entretanto, tratando-se de instituições de pesquisa, esse valor chamou atenção, pois se percebe que não existe uma cultura de participação nas instituições e esse é um fator que deve ser trabalhado em toda a comunidade acadêmica.

Foi estruturado um questionário subdividido em cinco partes. Ele atende a todos os itens solicitados pelo SINAES e também às ações já implementadas na rede mineira.

I - Caracterização do participante da pesquisa onde são questionados itens tais como dados demográficos; instituição e nível(is) concluído(s); localização regional, ocupação e área da ocupação atual. Totalizam 30 perguntas; dessas, oito são específicas para os egressos dos cursos técnicos, seis para os de graduação, seis para os de pós-graduação e dez a todos.

II - Caracterização dos egressos que estão no mundo de trabalho: tipo de trabalho; tempo para conseguir emprego e na atividade atual; satisfação com a atividade; localização hierárquica; renda; carga horária; exigência e oferta de vagas na área. São dez perguntas.

III - Caracterização dos egressos que estão estudando ou já concluíram outros cursos, seja no mesmo nível ou em outros níveis: são questões sobre o nível e a área dos novos cursos. São quatro perguntas que complementam as questões específicas da primeira parte.

IV - Avaliação institucional: além de perguntar se ainda há ligação com a instituição, utiliza a escala hedônica para medir, sob o ponto de vista do entrevistado, sua satisfação com diversos itens. São pedidas sugestões e é feito o convite para atualização do cadastro para contato posterior. São três questões mais diretas e uma tipo-Likert com 13 afirmações.

V - Avaliação do curso: são pedidos que na mesma ideia da escala hedônica sejam dados seus pontos de vista sobre o curso. Conta com sete questões, uma delas pede que faça a atualização dos contatos e outra traz 7 afirmações tipo-Likert. 
Algumas perguntas da primeira parte são informações que nas pesquisas de acompanhamento realizadas pelos campi, já pertencem ao próprio banco de dados institucional, e podem ser utilizadas para a estratificação da amostragem e, em alguns casos, podem ser retiradas do questionário, facilitando seu preenchimento, sem causar fadiga ao respondente, proporcionando respostas mais representativas e facilitando a análise.

Como descrito na metodologia, foram realizados pré-testes com os egressos o primeiro foi a disponibilização no portal IFSULDEMINAS, com o convite nas redes sociais para que os quase 1500 formados entre 2014 e 2018 respondessem. A chamada divulgou o período para participação entre 10 de março 2019 a 31 de agosto de 2019 (IFSULDEMINAS, 2020). A primeira população teve a participação de 622 ex-alunos, totalizando a participação de 41,5\%.

O segundo teste ocorreu com envio para e-mail dos ex-alunos das três instituições mineiras - CEFET-MG, IFMG e IFSULDEMINAS, que disponibilizaram 46683 endereços de e-mails dos formandos dos dez primeiros anos da RFEPCT, isto é, 2009 a 2018.

Houve uma redução de $11,3 \%$ na população devida a devolução dos e-mails enviados. Pouco mais de cinco mil, não foram entregues por diversos motivos, como "caixa cheia", "endereço não encontrado". Assim, a população ficou reduzida a 41418 participantes, representada por $43,7 \%$ egressos do CEFET-MG; $27,3 \%$ do IFMG e $29,0 \%$ do IFSULDEMINAS. Houve retorno de 2,6\% (1.087 participantes).

Vale ressaltar que o índice sugerido pelas autoras, Marconi e Lakatos (2005), não leva em consideração o período de distanciamento da instituição, no primeiro caso a participação pode ter sido maior porque o máximo de tempo passado após a formatura foi de cinco anos e no segundo teste do questionário de dez anos, mesmo que os ex-alunos ainda tivessem vínculo com as instituições os endereços eletrônicos, podem não estar mais acessíveis. E, também é preciso considerar que os dois os institutos participantes, já haviam realizado uma pesquisa semelhante poucos meses antes, o que pode levar ao desestímulo à participação e/ou ao entendimento do egresso de já ter respondido. Respectivamente 77,2\%; 10,9\% e 12,0\% foram os retornos correspondentes dos egressos do CEFET-MG, IFMG e IFSULDEMINAS.

A amostragem realizada para testar o instrumento, configura-se como não probabilística por conveniência. Caracteriza-se como um estudo de caso e não se pode afirmar nada sobre o nível de confiança. Essa é a estrutura amostral mais recorrente neste tipo de pesquisa.

Em ambos os testes, foi no primeiro mês que houve a maioria das respostas. E quando foram realizadas novas chamadas e, ou lembretes houve aumento na participação. Assim, sugere-se que três semanas depois de encaminhados os e-mails seja enviado um lembrete, informando que aqueles que querem participar da pesquisa, terão mais duas semanas para poderem participar e fechar o questionário com cinco ou seis semanas.

Os resultados específicos foram apresentados em relatórios e fogem do tema deste texto, a análise e tratamento dos pré-testes tiveram como objetivo aqui, melhorar do instrumento, testar as técnicas propostas, e pode-se afirmar que o questionário se mostrou viável e robusto pela convergência das questões. Para a avaliação da instituição e do curso, foram estimados o alfa de Cronbach, respectivamente, para o primeiro e segundo testes foram para a avaliação institucional 0,95 e 0,94 e para as questões referentes ao curso 0,94 e 0,92.

Foram segmentados e estimados os alfas de Cronbach, também segundo os níveis de ensino, técnico e de graduação; as áreas da atividade atual (área do curso, parcial, não estar na área e querer estar e não estar e não querer atuar); a ocupação atual (mercado de trabalho ou no 
sistema educacional). Com exceção aos respondentes que informaram não estar nem estudando e nem trabalhado, cujos alfas para a avaliação institucional $(0,90)$ e avaliação do curso $(0,80)$ todas as demais vinte e duas estimativas foram superiores a 0,91 .

Essa convergência é expressiva, visto que o formulário pode ser aplicado sem muitas influências de segmentações. Entretanto, a cada aplicação do questionário e/ou entrevista devese estudar a convergência das respostas, pois valores menores que 0,80 indicarão a existência de um segmento divergente e, por isso, deve ser analisado separadamente.

Após o teste da convergência sugere-se que a avaliação da instituição e do curso, proposta em 28 itens ${ }^{6}$ tipo-Likert, seja segmentada, deste modo, para facilitar a apresentação: a) influência de ter estudado na RFEPCT na vida do egresso; b) avaliação da instituição; c) relacionamento da comunidade acadêmica; d) infraestrutura da instituição; e) desenvolvimento de habilidades acadêmicas e profissionais; f) avaliação do próprio curso e g) contribuição do curso para a formação profissional.

Foi possível testar as técnicas propostas para estudos bivariados, como medidas de associação que demonstram se o ex-aluno possui ocupações diferentes, trabalho ou estudo; se continua atuando na área do curso concluído, associada ao nível de formação. Ao comparar o nível de profissionais formados pela rede desocupados, verifica-se que essa parcela é menor que a nacional. Além de se estimar a média de tempo para entrar no mercado de trabalho, há possibilidade de segmentar por raça, sexo, idade, curso e instituição.

As segmentações podem gerar informações para a atuação da gestão, mesmo em notas dentro do esperado. Por exemplo, na avaliação do curso, mesmo se a menor nota for para a adequação às exigências do mercado de trabalho, vinda de uma amostra, cujas respostas foram testadas como convergente e consistente, pode ser considerada um indicativo para adequações.

A periodicidade da aplicação dos questionários depende dos objetivos específicos. Como escrito anteriormente, os cursos de graduação devem ser avaliados anualmente por exigências legais, SINAES. Assim, acredita-se que o disparo de convites pelas redes sociais e, ou envio de convite por e-mails possa ser realizado anualmente, por convite, caracterizando um estudo de caso, por utilizar uma amostragem não probabilística por conveniência.

Sugere-se que cada formando seja entrevistado em ocasiões diferentes, gerando adequado acompanhamento do egresso, conforme sugerido por Paul (2015). De acordo com a pesquisa, o primeiro contato deve ocorrer entre seis meses e um ano, tempo médio informado para o primeiro emprego; e depois, em três e em cinco anos após a saída do primeiro curso concluído na Rede. Isso permitiria estabelecer se houve ascensão no mercado de trabalho para os profissionais que já trabalhavam durante o curso. Ainda, seria possível acompanhar, dentre os concluintes do curso técnico, aqueles que tiveram a verticalização no ensino e se, após cinco anos, já estariam no mercado de trabalho.

Se for proposta a continuidade do estudo, acompanhamento longitudinal do mesmo exaluno, deve ser incluída uma pergunta, informando ao participante a intenção de reenviar o questionário e se ele gostaria de participar. Para se conseguir a opinião dos empregadores, para obter informações que possam atestar a coerência dos conteúdos curriculares com as necessidades do mercado de trabalho e embasar a continuidade ou modificações das atividades

\footnotetext{
${ }^{6}$ Ainda é preciso reforçar que podem ser adicionadas outras questões para atender a objetivos específicos.
} 

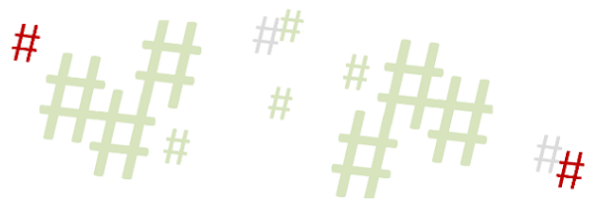

formativas, faz-se necessário conhecer o ponto de vista dos empregadores, e para tanto é necessária a aplicação de um questionário.

O teste do questionário foi feito com as empresas que ofertaram estágios em 2018 aos discentes do IFSULDEMINAS. Do total de 4.043 empresas, menos da metade $(44,1 \%)$ divulgava os endereços eletrônicos. Por campus, essa informação variou de zero a 76,6\%. Ao encaminhar os e-mails com o link para a pesquisa, a amostra foi reduzida mais uma vez, por causa da devolução desses e-mails por "endereço não encontrado", entre outras mensagens semelhantes. Assim, totalizaram-se 1.687 e-mails enviados que correspondem a 41,7\% das empresas. Após 21 dias do primeiro convite, foi encaminhado um lembrete para participação. Houve 37 empresas respondentes $(2,19 \%)$, mesmo depois do lembrete. Novamente, não é possível afirmar se todos os envios foram entregues (recebidos).

Os resultados específicos também foram apresentados e publicados, mas, da mesma forma que os resultados para os egressos, fogem do foco deste texto. Não foi possível testar as associações bivariadas entre área de abrangência da empresa espacialmente, ramo de atuação e porte, devido ao número de participantes, mas essas questões poderão servir para segmentar a opinião dos participantes sobre questões referentes aos fatores que influenciaram a contratação de funcionário e na manutenção de ofertas de vagas para estagiários. Deve-se utilizar um teste, por exemplo, o C*, para inferir se há associação entre as opiniões e as segmentações possíveis, sobre a avaliação institucional e a aplicabilidade da teoria para o mercado de trabalho.

Mesmo com baixa representatividade, foi possível fazer o pré-teste do questionário e estimar o alfa de Cronbach em 0,97. Portanto, pode-se afirmar que o questionário é consistente e que existe convergência das respostas dos participantes. É necessário, como nas outras possibilidades de acompanhamento, um banco de dados com endereços eletrônicos e, ou telefônicos, para envios que facilitem selecionar uma amostra, visto que as empresas não possuem vínculo direto com a RFEPCT. Por essa razão, o questionário on-line censitário não é o indicado, pois haverá motivações pessoais da empresa na participação. E mesmo que seja adotado esse tipo de instrumento depois do tempo de retorno, os responsáveis pelas empresas, que não responderam ao questionário devem ser contatados por meio telefônico para completar a amostragem. Para isso, seria necessário um identificador no questionário.

Prioritariamente, é essencial construir um banco de fácil acesso, ou que sejam propostas outras populações, sendo necessária uma padronização das informações, pois mesmo dentro de um único instituto não existe padrão nas planilhas de dados.

Como o banco de dados das empresas não é tão automático, o estudo para a estruturação do instrumento de pesquisa resultou em algumas ideias para a obtenção desses contatos:

a) Continuar a pesquisa com os possíveis empregadores para estruturar o banco de dados com informações de todas empresas que ofertaram estágios no ano anterior, e-mails e telefones. Sugere-se a utilização de uma amostra por conglomerados.

b) Trabalhar com as associações comerciais locais, por censo ou por amostragem estratificada, para conhecer a opinião das empresas das áreas dos cursos ofertados, sobre a compatibilidade entre a capacitação profissional e o mercado de trabalho.

c) Utilizar os contatos informados na pesquisa realizada com os egressos, que informou o contato da empresa em que trabalha. Segundo Vinuto (2014), essa amostragem nãoprobabilística é nomeada "bola de neve" - o egresso funcionaria como semente e indicaria o próximo pesquisado, por saber que ele poderá dar informações de assunto restrito, neste caso, sobre a formação do profissional pela rede. 
d) Completar o estudo proposto pelo CEFET-MG que, em 2020, buscou, junto ao Ministério da Economia, autorização para acessar e analisar os dados da RAIS/TEM, visando estudar quantitativamente a colocação de seus ex-alunos no mercado de trabalho formal. Essa relação das empresas poderia ser utilizada como banco de dados para envio do questionário de forma censitária ou por seleção da amostra probabilística.

Com as análises das respostas das duas pesquisas com os egressos e da primeira rodada com os possíveis empregadores, foram propostas adequações aos questionários e segmentações, de modo que podem ser aplicados em níveis e modalidades específicas; tanto para a população de egressos, quanto para a população dos responsáveis pelas empresas.

Resumindo, o Programa de Acompanhamento de Egressos da RFEPCT proposto reúne as possibilidades de análise documental e de banco de dados institucional; contato com egressos e empregadores, além de todos os objetivos específicos que possam surgir. Deve ser configurado por essas frentes, de forma a englobar a opinião de todos os envolvidos, profissionais formados e empregadores e não apenas os números de formandos. Tais informações haverão de nortear os gestores na tomada de decisão de manutenção e, ou de realizar modificações curriculares; e ajudar a comunidade na decisão de qual nível, curso e modalidade escolher para iniciar ou mesmo aprofundar os estudos. Sendo assim, sugere-se que a apresentação desses resultados não fique só nas esferas acadêmicas como publicações em periódicos, mas que seja disponibilizada a toda a sociedade.

Sugere-se que a periodicidade seja no mínimo anual, e com repetições planejadas com a mesma população sendo avaliada longitudinalmente; que os testes básicos para estimar associação e consistência das respostas sejam realizados para que as inferências possam ser comparadas; que o tempo de espera para retorno não ultrapasse seis semanas, pois, como apreendido nas revisões bibliográficas e nas três pesquisas realizadas, após um mês de enviado o convite, o acréscimo no número de respondentes não é significativo, exceto que haja outras chamadas ou lembretes.

Foi proposto um protocolo para acompanhamento dos egressos com sugestões do delineamento amostral, definido pelo objetivo da pesquisa, além de um formulário com o questionário mínimo, tanto para os egressos quanto para os empregadores, ainda passível de ser reestruturado para atender a demandas específicas. Foram propostas técnicas estatísticas para avaliar as respostas dos questionários, inferir sobre a significância dos dados encontrados e sugestões de apresentação. Entretanto, indica-se que, principalmente depois de já comprovadas as significâncias, associações, convergências e coerências nas respostas ao questionário, sejam realizadas melhorias nas apresentações, utilizando-se técnicas de Dahboard, que possibilitem a visualização das informações de forma a melhorar a gestão dessas informações. Conforme sugere Alhadad (2018), sobre o uso de ferramentas de visualização, pode-se melhorar as inferências e torná-las menos tendenciosas e mais precisas.

A metodologia para aplicação dos questionários até a análise de associações e convergências das questões que foi testada será disponibilizada posteriormente. Pretende-se também ofertar capacitações aos servidores para o levantamento e o tratamento dos dados. 


\section{Considerações Finais}

Partindo da proposta de iniciar uma padronização do Programa de Acompanhamento de Egressos da RFEPCT, foi necessário estruturar um questionário mínimo para abranger a complexidade da Rede, do ponto de vista dos ex-alunos e dos possíveis empregadores.

Foram propostas técnicas estatísticas que podem ser reproduzidas de forma simples e longitudinalmente, possibilitando realizar comparações e gerar informações capazes de auxiliar na avaliação das Políticas Públicas e dos Programas de Educação Profissional e na flexibilização e na atualização dos currículos, para atender demandas locais e regionais.

Para que exista uma rotina planejada de Acompanhamento de Egressos, preferencialmente constituindo parte do calendário acadêmico, sugere-se que a efetivação dessa pesquisa seja feita pela CPA e, ou pela Pró-Reitoria de Extensão ou equivalente, visto que essas já devem atender à legislação vigente para os ensinos superiores. Sugere-se, também, que seja feito um cadastro no último semestre do curso, inscrevendo os discentes, e que sejam feitas três rodadas de aplicações: seis meses a um ano; três anos; e cinco anos após a formatura.

Em relação ao ponto de vista do empregador sobre o profissional formado pela RFEPCT, é necessário que a população seja ampliada, para se atingir maior representatividade, e que se conduzam pesquisas com objetivos mais restritos.

Conclui-se que ainda é necessário discutir e aprimorar as técnicas e as logísticas adotadas, no protocolo proposto, primando-se pela padronização dos bancos de dados e pelo incentivo à cultura de participação em pesquisas, em toda a comunidade acadêmica.

\section{Financiamento e agradecimentos}

Ao IFSULDEMINAS, por facilitar a condução desta pesquisa e o aprimoramento das práticas de trabalho por meio deste projeto.

Aos funcionários do CEFET-MG, IFMG e IFSULDEMINAS, por facilitarem a condução desta pesquisa, ao disponibilizarem os bancos de dados necessários. Aos egressos participantes, por responderem ao instrumento de coleta de dados.

Ao Observatório da Educação Profissional e Tecnológica, antigo Observatório do Mundo do Trabalho de Minas Gerais, por disponibilizar o Edital que proporcionou o desenvolvimento desta pesquisa.

\section{Referências}

ALHADAD, S. S. J. Visualizing Data to Support Judgement, Inference, and Decision Making in Learning Analytics: Insights from Cognitive Psychology and Visualization Science.

Journal of Learning Analytics. v. 5, n. 2, p. 60-85, 2018.

ANDRADE, E. L. de. BARBOSA, N. B. Políticas públicas de educação profissional e a inserção de egressos no mercado de trabalho. Trabalho \& Educação. Belo Horizonte, v. 26 n. 2, 171-187. Disponível em: <https://periodicos.ufmg.br/index.php/trabedu/article/view/9657/6847>. Acesso em: 10 maio 2020. 
BRASIL. Ministério da Educação Instituto Nacional de Estudos e Pesquisas Educacionais Anísio Teixeira (Inep) Comissão Nacional de Avaliação da Educação Superior (Conaes) Roteiro de Auto-avaliação Institucional: Orientações Gerais. Brasília: INEP, 2004. Acesso em: 10 maio 2020.

BRASIL. Ministério da Educação (MEC). Pesquisa nacional de egressos dos cursos técnicos da Rede Federal de Educação Profissional e Tecnológica (2003-2007). Brasília: MEC, 2007.

BRASIL. Lei n. 11. 892, de 29/12/2008. Institui a Rede Federal de Educação Profissional, Científica e Tecnológica, cria os Institutos Federais de Educação, Ciência e Tecnologia, e dá outras providências. 2008. Disponível em: < http://www.planalto.gov.br/ccivil_03/_Ato20072010/2008/Lei/L11892.htm > Acesso em: 10 maio 2020.

BRASIL. Instituto Nacional de Estudos e Pesquisas Educacionais (INEP). Sistema Nacional de Avaliação da Educação Superior SINAES: política institucional de integração e de avaliação do egresso na melhoria da IES. v. 3. 2015. 79 p. Disponível em:

<http://portal.inep.gov.br/documents/186968/484109/SINAES+> Acesso em: 10 maio 2020.

BRASIL. Ministério da Saúde. Conselho Nacional de Saúde. Resolução CNS 510/2016, de 07/04/2016. Disponível em: <https://bit.ly/2FNpb7T> Acesso em: 10 maio 2020.

BRASIL. Ministério da Educação. Secretaria de Educação Profissional e Tecnológica. 2019. Disponível em: <https://www.plataformanilopecanha.org/\#/login>. Acesso em: 10 maio 2020.

BRASIL. Ministério da Educação. Portal da Rede Federal de Educação Profissional, Científica e Tecnológica. 2020. Disponível em: <http://redefederal.mec.gov.br/>. Acesso em: 10 maio 2020.

BROW, J. D. Likert items and scales of measurement? SHIKEN: JALT Testing \& Evaluation SIG Newsletter. Cambridge, v.15, n.1, p. 10-14. March. 2011. Disponível em: <http://hosted.jalt.org/test/PDF/Brown34.pdf>. Acesso em: 10 maio 2020.

CHAUÍ, M. A universidade operacional. Avaliação, Campinas, ano 1, n. 1, p. 3-8, jun. 1999.

COSTA, P. L. A., MARINHO, R. J. A. Educação profissional e tecnológica brasileira reinstitucionalizada: uma visão geral dos embates sobre a aprovação dos IFs. In: FRIGOTTO, G. (Org.). Instituto Federais de Educação, Ciência e Tecnologia: relação com o ensino médio integrado e o projeto societário de desenvolvimento. Rio de Janeiro: Carmen da Matta, 2018. p. 63-81.

CRONBACH, L. J. Coefficient alpha and the internal structure of test. Psychometrika. 1951.

DELUIZ, N. et al. Metodologias e resultados do acompanhamento de egressos da educação profissional. Seminário Nacional de Educação Profissional, Brasília, jun./2003. Disponível em: <http://portal.mec.gov.br/setec/arquivos/pdf1/gt13.pdf> Acesso em: 10 maio 2020. 
FERREIRA, D. F. Estatística básica. Lavras: Editora UFLA, 2. ed. Amp. e Rev. 2009. 664 p.

FERREIRA, N. S. A. As pesquisas denominadas "Estado da Arte". Educação \& Sociedade, ano XXIII, n. 79, p. 257- 272. ago. 2002.

FRANCISCO, C. S.; PELUCIO, J. S.; CAMPOS, K. A. Acompanhamento dos egressos dos cursos superiores do IFSULDEMINAS. In: XI Jornada Científica e Tecnológica e VIII Simpósio de Pós-Graduação do IFSULDEMINAS, 2019, Inconfidentes. 11. Jornada Científica e Tecnológica e 8. Simpósio da Pós-Graduação do IFSULDEMINAS, 2019.

FRIGOTTO, G. (org.). Institutos Federais de Educação, Ciência e Tecnologia: relação com o ensino médio integrado e o projeto societário de desenvolvimento. Rio de Janeiro: UERJ, LPP. 2018. 320p.

GOOGLE. Google. Disponível em: <https://www.google.com/forms/about/>. Acesso em: 10 maio 2020.

INSTITUTO FEDERAL DE MINAS GERAIS (IFMG). Grupo Observatório da EPT se reúne na Reitoria do IFMG. 2019. Disponível em:

$<$ https://www.ifmg.edu.br/portal/extensao/observatorio-do-mundo-do-trabalho/eventos/grupoobservatorio-da-rede-da-ept-se-reune-na-reitoria>. Acesso em: 10 maio 2020.

INSTITUTO FEDERAL DO SUL DE MINAS GERAIS (IFSULDEMINAS). Ministério da Educação. Plano de Desenvolvimento Institucional. 2014. Disponível em: $<$ https://portal.ifsuldeminas.edu.br/images/PDFs/acoes_e_programas_/PDI20142018Ifsuldeminas.pdf $>$. Acesso em: 10 maio 2020.

INSTITUTO FEDERAL DO SUL DE MINAS GERAIS (IFSULDEMINAS). Egressos. 2020. Disponível em: <https://portal.ifsuldeminas.edu.br/index.php/pro-reitoriaextensao/egressos>. Acesso em: 10 maio 2020.

LEITE, M. Ensino integrado no IFSULDEMINAS - do documento à implantação: um olhar pela janela da governamentalidade. Tese. (Doutorado em Educação). Programa de Pós-graduação em Educação. Universidade de São Francisco. Itatiba, 2015. Disponível em: <https://www.usf.edu.br/galeria/getImage/427/13281046841815973.pdf >. Acesso em: 10 maio 2020.

LIRA, S. A., CHAVES NETO, A. Coeficientes de correlação para variáveis ordinais e dicotômicas derivados do coeficiente linear de Pearson. RECIE. Uberlândia, v. 15, n. 1/2, p. 45-53, jan.-dez., 2006.

MACHADO, G. R. Um estudo do perfil demandado pelo mercado de trabalho para os alunos egressos da estola técnica da Universidade Federal do Rio Grande do Sul. Dissertação (Mestrado Profissionalizante em Engenharia). Universidade Federal do Rio Grande do Sul. Porto Alegre, 2002. 
MANZKE, G.; GONZALES SALLER, A.; LIMA GIL, R. Ensino Médio Integrado: preparação para o ENEM ou para o mercado de trabalho? Anais do Salão Internacional de Ensino, Pesquisa e Extensão, v. 5, n. 4, 2013. Disponível em:

<https://periodicos.unipampa.edu.br/index.php/SIEPE/article/view/66295>. Acesso em: 10 maio 2020.

MARCONI, M. A.; LAKATOS, E. M. Fundamentos de metodologia científica. 6. ed. São Paulo: Atlas, 2005. 301p.

MORAES FILHO, I.M.; CARVALHO FILHA, F.S.S.; ALMEIDA, R.J. O currículo no ensino superior: adequações necessárias para o despertar dos egressos. Rev. Cient. Sena Aires. 2017, v. 6, n. 1, p. 1-2. Disponível em: <http://revistafacesa.senaaires.com.br/index. php/revisa/article/view/270>. Acesso em: 10 maio 2020.

OLIVEIRA, P. H. F. C. Amostragem básica: aplicação em auditoria. Rio de Janeiro.: Editora Moderna, 2. ed., 2014. 320p.

PAUL, J. J. Acompanhamento de egressos do ensino superior: experiência brasileira e internacional. Caderno CRH. Salvador. v. 28, n. 74, p. 309-326. maio/ago., 2015.

RIBEIRO, R. H. D.; CAMPOS, K. A. Os egressos dos cursos técnicos do IFSULDEMINAS: questionário respondido em redes sociais por adesão. In: XI Jornada Científica e Tecnológica e VIII Simpósio de Pós-Graduação do IFSULDEMINAS, 2019, Inconfidentes. 11. Jornada Científica e Tecnológica e 8. Simpósio da Pós-Graduação do IFSULDEMINAS, 2019.

SAMPAIO, M. V. D. Educação profissional: a expansão recente do IFRN e a absorção local de egressos no mercado de trabalho. Dissertação (Mestrado em Economia). Programa de Pós-graduação em Economia. Universidade Federal do Rio Grande do Norte (UFRN). Natal, RN, 2013. Disponível em: 〈http://goo.gl/98Jbf0>. Acesso em: 10 maio 2020.

VINUTO, J. A amostragem em bola de neve na pesquisa Qualitativa: um debate em aberto. Temáticas, Campinas, v. 22, n. 44, p. 203-220, ago./dez. 2014.

Recebido em maio de 2020.

Aprovado em novembro de 2020. 